\title{
Berberine induces apoptosis and DNA damage in MG-63 human osteosarcoma cells
}

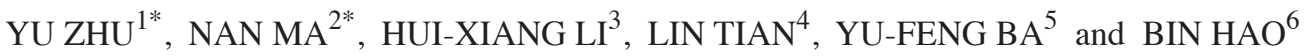 \\ ${ }^{1}$ Department of Orthopedic Surgery, The Second Affiliated Hospital of Zhengzhou University, Zhengzhou, Henan 450014; \\ Departments of ${ }^{2}$ Interventional Radiology and ${ }^{3}$ Pathology, The First Affiliated Hospital of Zhengzhou University, Zhengzhou, \\ Henan 450052; ${ }^{4}$ Department of Medicine, Zhengzhou Ninth People's Hospital, Zhengzhou, Henan 450014; \\ ${ }^{5}$ Department of Thoracic Surgery, The Affiliated Tumor Hospital of Zhengzhou University (Henan Tumor Hospital), \\ Zhengzhou, Henan 450008; ${ }^{6}$ Department of Urology, The Second Affiliated Hospital of \\ Zhengzhou University, Zhengzhou, Henan 450014, P.R. China
}

Received September 19, 2013; Accepted November 19, 2013

DOI: $10.3892 / \mathrm{mmr} .2014 .2405$

\begin{abstract}
Berberine, an isoquinoline alkaloid extracted from the dry root of Coptidis Rhizoma, has been found to exhibit marked anticancer effects on a panel of established cancer cells. Among the human osteosarcoma lines treated, MG-63 cells were found to be the most sensitive. The present study investigated the potential genotoxic effect of berberine on MG-63 human osteosarcoma cells. The effect of berberine on cell viability was determined using a 3-(4,5-dimethylthiazol-2-yl)-2,5-diphenyltetrazolium bromide assay and cell apoptosis was analyzed by flow cytometry and a DNA ladder assay. $\gamma \mathrm{H} 2 \mathrm{AX}$ focus formation was used to detect DNA damage in MG-63 cells. Berberine induced a significant increase in apoptosis in MG-63 cells in a concentration- and time-dependent manner, as determined by DNA fragmentation analysis and flow cytometry. Furthermore, berberine induced significant concentration- and time-dependent increases in DNA damage compared with that in the negative control. In conclusion, these observations indicated that berberine induced apoptosis and DNA damage in MG-63 cells.
\end{abstract}

\section{Introduction}

Osteosarcoma is a cancerous bone tumor that usually develops in adolescents (1). Significant improvements in patient survival rates have been achieved in recent years. Bioactive compounds derived from natural products have been used

Correspondence to: Dr Bin Hao, Department of Urology, The Second Affiliated Hospital of Zhengzhou University, 2 Jingba Road, Zhengzhou, Henan 450014, P.R. China

E-mail: tougao0101@163.com

*Contributed equally

Key words: berberine, DNA damage, apoptosis, $\gamma \mathrm{H} 2 \mathrm{AX}$ foci, DNA fragmentation for thousands of years for therapy, pre-dating recorded history (2). Berberine, an isoquinoline alkaloid derived from the Chinese herb Huanglian, is used as a botanical drug (3). In China, berberine is commonly prescribed for the treatment of gastrointestinal complaints, diarrhea and other conditions. Accumulative evidence from in vitro studies has demonstrated that berberine possesses anticancer and anti-inflammatory activity in different types of human cancer cells, including osteosarcoma (4), epidermoid carcinoma (5), lung cancer (6), melanoma (7), prostate cancer (8) and liver cancer (9) cells. Animal studies have demonstrated that berberine is able to suppress chemical-induced carcinogenesis (10), tumor formation (11) and tumor invasion $(12,13)$. Apoptosis and DNA damage have previously been revealed to be effective in eliminating cancer cells. Numerous natural compounds, including berberine, have been developed as preventive and treatment agents against cancer. However, to the best of our knowledge, few studies have examined the potential therapeutic effects of berberine in osteosarcoma.

The present study examined the effects of berberine on MG-63 cells in culture using DNA fragmentation analysis and flow cytometry. It has previously been demonstrated that the formation of DNA double-strand breaks induces $\gamma \mathrm{H} 2 \mathrm{AX}$ aggregations in nuclei, and it has been suggested that $\gamma \mathrm{H} 2 \mathrm{AX}$ focus formation is a sensitive method for detecting DNA double-strand breaks (14). A threshold of $\geq 4 \gamma \mathrm{H} 2 \mathrm{AX}$ foci/cell has been found to be optimal for the determination of DNA damage (15). Thus the extent of DNA damage was observed in berberine-treated cells, as determined by measuring $\gamma \mathrm{H} 2 \mathrm{AX}$ focus formation.

\section{Materials and methods}

Drugs and materials. Berberine (purity, >98\%) was purchased from Tianping Pharmaceutical Co. (Shanghai, China). The compound was dissolved in dimethyl sulfoxide (DMSO). N-methyl-N'-nitro-N-nitrosoguanidine (MNNG), normal-melting agarose, 4',6-diamidino-2-phenylindole (DAPI), 3-(4,5-dimethylthiazol-2-yl)-2,5-diphenyltetrazolium bromide (MTT), Tween-20 and paraformaldehyde were 
obtained from Sigma Chemical Co. (Silicon Valley, CA, USA). The apoptosis detection kit was obtained from BD Pharmingen (San Diego, CA, USA). Triton X-100, fetal bovine serum (FBS), xylene cyanol and bromophenol blue were obtained from Sangon Biotech Shanghai Co., Ltd. (Shanghai, China). All other chemicals were purchased from Sinopharm Chemical Reagent Co., Ltd. (Shanghai, China).

Cell culture. The MG-63 human osteosarcoma cell line (wild type) was purchased from the Cell Bank of Type Culture Collection of the Chinese Academy of Sciences (Shanghai, China). The cells were cultured in Dulbecco's modified Eagle's medium supplemented with $10 \%$ heat-inactivated FBS, penicillin $(100 \mathrm{U} / \mathrm{ml})$ and streptomycin $(100 \mathrm{U} / \mathrm{ml})$. The cells were incubated at $37^{\circ} \mathrm{C}$ in a $5 \% \mathrm{CO}_{2}$ incubator. The medium was exchanged once every two days. Following treatment, the cells were harvested by trypsinization.

Analysis of cytotoxicity. The cytotoxicity was determined using the MTT assay (16). MG-63 cells were seeded at a density of $1 \times 10^{4}$ cells/well in $100 \mu 1$ of cell culture medium and then placed in a 96-well plate. Following $12 \mathrm{~h}$ of incubation, the cells were treated with $0-80 \mu \mathrm{M}$ berberine for 12 and $24 \mathrm{~h}$. MTT solution $(5 \mathrm{mg} / \mathrm{ml})$ was then added to each well and the samples were incubated at $37^{\circ} \mathrm{C}$ for $4 \mathrm{~h}$. Subsequently, the supernatant was removed and replaced with $100 \mu \mathrm{l}$ DMSO. The optical density of the control and drug-treated wells was measured using an automated microplate reader (Multiskan Ex; Ani Lab systems Ltd., Vantaa, Finland) at a test wavelength of $570 \mathrm{~nm}$.

Flow cytometric analysis of berberine-induced apoptosis in MG-63 cells. To determine the externalization of phosphatidylserine by fluorescein isothiocyanate (FITC)-labeled Annexin V and propidium iodide (PI), flow cytometry was used as previously described (17). Briefly, the cells were treated with berberine at concentrations of 20, 40, 60 and $80 \mu \mathrm{M}$ for 12 and $24 \mathrm{~h}$. The cells were washed twice with cold phosphate-buffered saline (PBS) and resuspended in $500 \mu \mathrm{l}$ binding buffer at a concentration of $1 \times 10^{6}$ cells $/ \mathrm{ml}$. Then, $5 \mu \mathrm{l}$ Annexin V-FITC solution and $5 \mu \mathrm{l}$ PI $(1 \mathrm{mg} / \mathrm{ml})$ were added. The cells were incubated at $37^{\circ} \mathrm{C}$ for $30 \mathrm{~min}$ and analyzed by flow cytometry within $1 \mathrm{~h}$. The number of apoptotic cells were counted and presented as a percentage of the total cell count.

DNA extraction and detection of DNA fragmentation. The DNA ladder assay was performed as previously described (18), with slight modifications. After treating the cells with berberine and MNNG at concentrations of 50 and $20 \mu \mathrm{M}$, respectively, for $24 \mathrm{~h}$, pellets containing $1 \times 10^{6}$ cells were lysed in lysis buffer $[10 \mathrm{mM}$ Tris-HCl ( $\mathrm{pH} 8.0), 25 \mathrm{mM}$ ethylenediaminetetraacetic acid (EDTA), $0.5 \%$ sodium dodecyl sulfate, $100 \mathrm{mM} \mathrm{NaCl}$ and $400 \mathrm{~g} / \mathrm{ml}$ protease $\mathrm{K}]$ for $120 \mathrm{~min}$ at $56^{\circ} \mathrm{C}$ and then treated with $10 \mathrm{mg} / \mathrm{ml}$ RNase A for an additional $50 \mathrm{~min}$ at $37^{\circ} \mathrm{C}$. The lysates were centrifuged $(12,000 \mathrm{x} \mathrm{g}$ for $30 \mathrm{~min}$ at $4^{\circ} \mathrm{C}$ ) and the supernatant was collected. The fragmented DNA was extracted from the supernatant with a neutral phenol:chloroform:isoamyl alcohol mixture (v/v/v; 25:24:1). The DNA pellet was precipitated by adding isopropanol, washed with $75 \%$ ethanol and dissolved in Tris-EDTA buffer

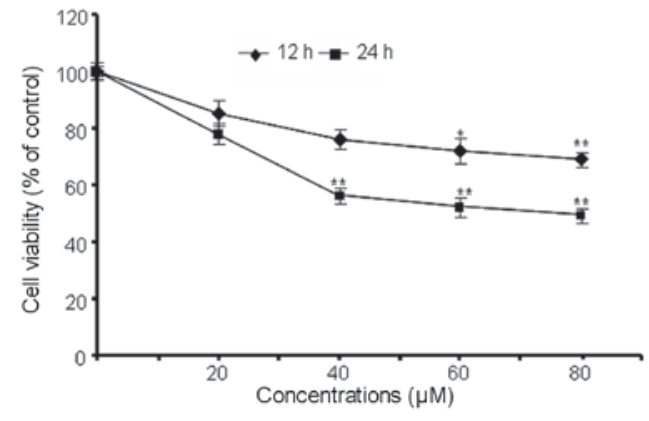

Figure 1. Cytotoxicity of berberine in MG-63 cells. The cells were treated for 12 and $24 \mathrm{~h}$ in the presence of berberine. Cell viability was then determined using a 3-(4,5-dimethylthiazol-2-yl)-2,5-diphenyltetrazolium bromide assay and expressed as the mean \pm standard error of the mean of three separate experiments. ${ }^{*} \mathrm{P}<0.05$ and ${ }^{* *} \mathrm{P}<0.01$, compared with the control.

(10 mM Tris- $\mathrm{HCl}$ and $1 \mathrm{mM}$ EDTA; $\mathrm{pH}$ 8.0). DNA fragmentation was detected by gel electrophoresis and the bands were stained with ethidium bromide for UV light visualization.

$\gamma H 2 A X$ focus staining. The phosphorylation of histone H2AX (a marker of DNA double-strand breaks) was analyzed as previously described (15), with slight modifications. Briefly, $1 \times 10^{5}$ cells were seeded into 6-well culture plates containing a glass cover slip in each well. Following treatment, the cells were fixed in $4 \%$ paraformaldehyde for $15 \mathrm{~min}$, washed with PBS and permeabilized in $0.2 \%$ Triton X-100. Following inhibition with blocking serum for $1.5 \mathrm{~h}$, the samples were incubated with a mouse monoclonal anti-H2AX antibody (1:1,000; Cell Signaling Technology, Inc., Boston, MA, USA) for $2 \mathrm{~h}$, followed by incubation with FITC-conjugated goat anti-mouse secondary antibody (1:500; Cell Signaling Technology, Inc.) for $1 \mathrm{~h}$. For staining the nuclei, DAPI was added to the cells and incubated for another $15 \mathrm{~min}$. The cover slip was then removed from the plate, mounted on a glass slide and observed using an Olympus BX53 fluorescent microscope (Olympus, Tokyo, Japan)

Statistical analysis. Data are expressed as the mean \pm standard error of the mean of three independent experiments. The differences among the treated groups and the negative control were compared by one-way analysis of variance. The Newman-Keuls multiple comparisons test was applied. $\mathrm{P}<0.05$ was considered to indicate a statistically significant difference. All statistical analyses were performed using SPSS 17.0 (SPSS, Inc., Chicago, IL, USA).

\section{Results}

Cytotoxic effect of berberine on MG-63 cells. The results of the trypan MTT assay demonstrated that berberine induced a concentration- and time-dependent decrease in the viability of MG-63 cells compared with the control (Fig. 1), indicating that berberine has cytotoxic effects on MG-63 cells.

Berberine induced apoptosis in MG-63 cells. Annexin V/PI staining was used to analyze whether the loss of cell viability induced by berberine was associated with apoptosis. Fig. 2 shows the rate of cell apoptosis detected by double-labeling 
A

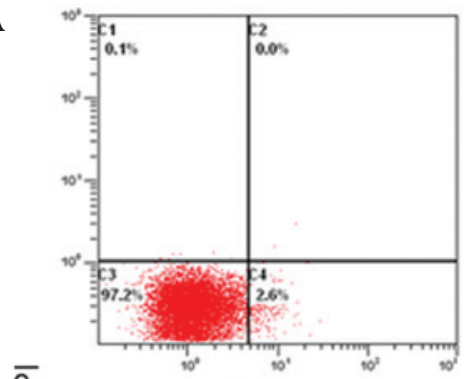

$\bar{\alpha}$

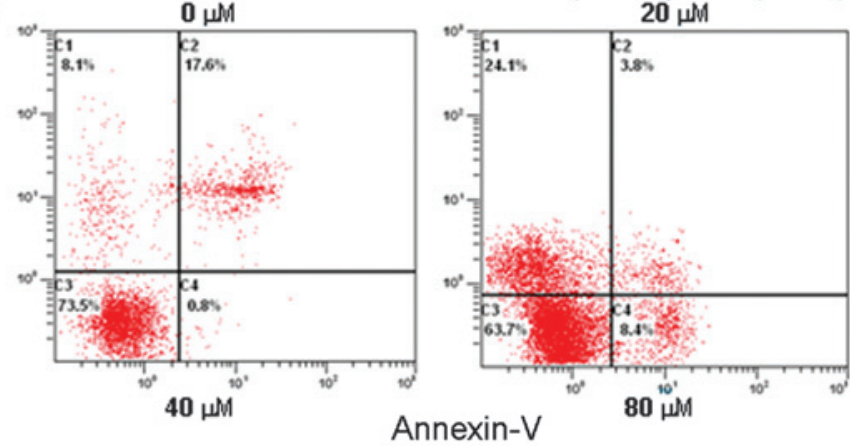

B

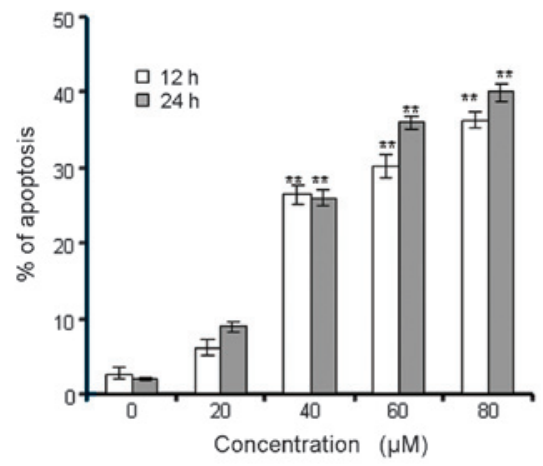

Figure 2. Berberine induces apoptosis in MG-63 cells. (A) Flow cytometric analysis of apoptosis using Annexin-V and PI double staining (12 h). (B) Apoptotic incidences of MG-63 cells treated with $0,20,40,60$ or $80 \mu \mathrm{M}$ berberine for 12 and $24 \mathrm{~h}$. ${ }^{*} \mathrm{P}<0.05$ and ${ }^{* *} \mathrm{P}<0.01$, compared with control. PI, propidium iodide.

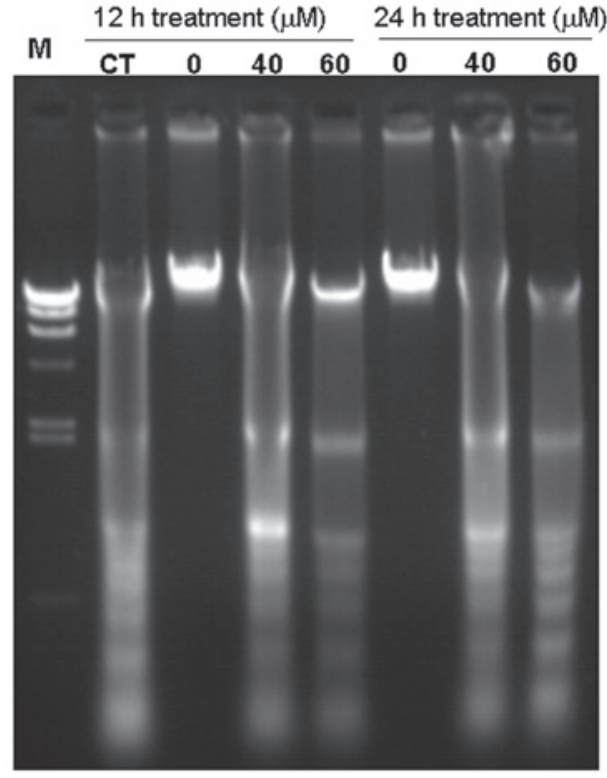

Figure 3. Berberine induces apoptosis-associated DNA fragmentation in MG-63 cells by the separation of urea polyacrylamide gel electrophoresis $\mathrm{M}$, marker (1 kb DNA ladder); CT, a positive control of methylnitronitrosoguanidine $(20 \mathrm{mM})$.

flow cytometry with Annexin V and PI. A concentration- and time-dependent increase was observed in the apoptotic rate of MG-63 cells exposed to berberine. The apoptotic rates of MG-63 cells treated with berberine at 20, 40,60 and $80 \mu \mathrm{M}$ increased to $6.1 \pm 1.1,26.5 \pm 1.3,30.2 \pm 2.8$ and $36.3 \pm 1.0 \%$ following $12 \mathrm{~h} ; 9.0 \pm 0.7,26.1 \pm 1.5,36.4 \pm 1.8$ and $40.0 \pm 1.2 \%$ following $24 \mathrm{~h}$, respectively. By contrast, the control cells showed apoptosis rates of only $2.8 \pm 0.8$ and $2.0 \pm 0.2 \%$ following 12 and $24 \mathrm{~h}$, respectively (Fig. 2B). Furthermore, it was revealed that berberine induced significant DNA fragmenta- tion in MG-63 cells (Fig. 3). DNA fragmentation was observed in cells treated with berberine at 40 and $60 \mu \mathrm{M}$ following 12 and $24 \mathrm{~h}$. These results suggest that the anticancer activity of berberine involves the induction of apoptosis.

$\gamma H 2 A X$ foci show DNA double-strand breaks are induced by berberine. The immunofluorescent images of histone $\mathrm{H} 2 \mathrm{AX}$ phosphorylation in $\gamma \mathrm{H} 2 \mathrm{AX}$-stained MG-63 cells are shown in Fig. 4. Treatment with berberine resulted in time-dependent induction of $\gamma \mathrm{H} 2 \mathrm{AX}$ foci. In the control group, MG-63 cells had few $\gamma \mathrm{H} 2 \mathrm{AX}$ foci in the nuclei, with only $\sim 6 \%$ of cells containing more than four foci (Fig. 5). Berberine and MNNG treatment induced foci formation and increased the percentage of $\gamma \mathrm{H} 2 \mathrm{AX}$-positive cells. The data in Fig. 5 show that berberine and MNNG exhibited distinct concentration- and time-dependent effects $(\mathrm{P}<0.01)$ on $\gamma \mathrm{H} 2 \mathrm{AX}$ foci formation in MG-63 cells.

\section{Discussion}

Over the past decade, interest in the pharmacological effects of bioactive compounds with respect to use in cancer treatments and for cancer prevention has markedly increased (19). Accumulating evidence has demonstrated a correlation between natural compounds and cancer prevention $(5,6,9,20)$. Thus, evaluation of ancient medicinal herbs may provide the basis for the development of chemopreventive methods and strategies. Berberine was used widely in ancient therapeutic medicinal practices (3). It has been demonstrated to exert numerous anticancer activities in various types of cancer cells through different cytotoxic effects (21). Previous studies have demonstrated that human osteosarcoma cells (U2OS, Saos-2 and HOS) treated with berberine exhibited cell cycle arrest and apoptosis (4).

The present study found that berberine (20-80 $\mu \mathrm{M})$ inhibited growth of MG-63 cancer cells through induction of apoptosis and DNA damage in vitro. Furthermore, berberine 


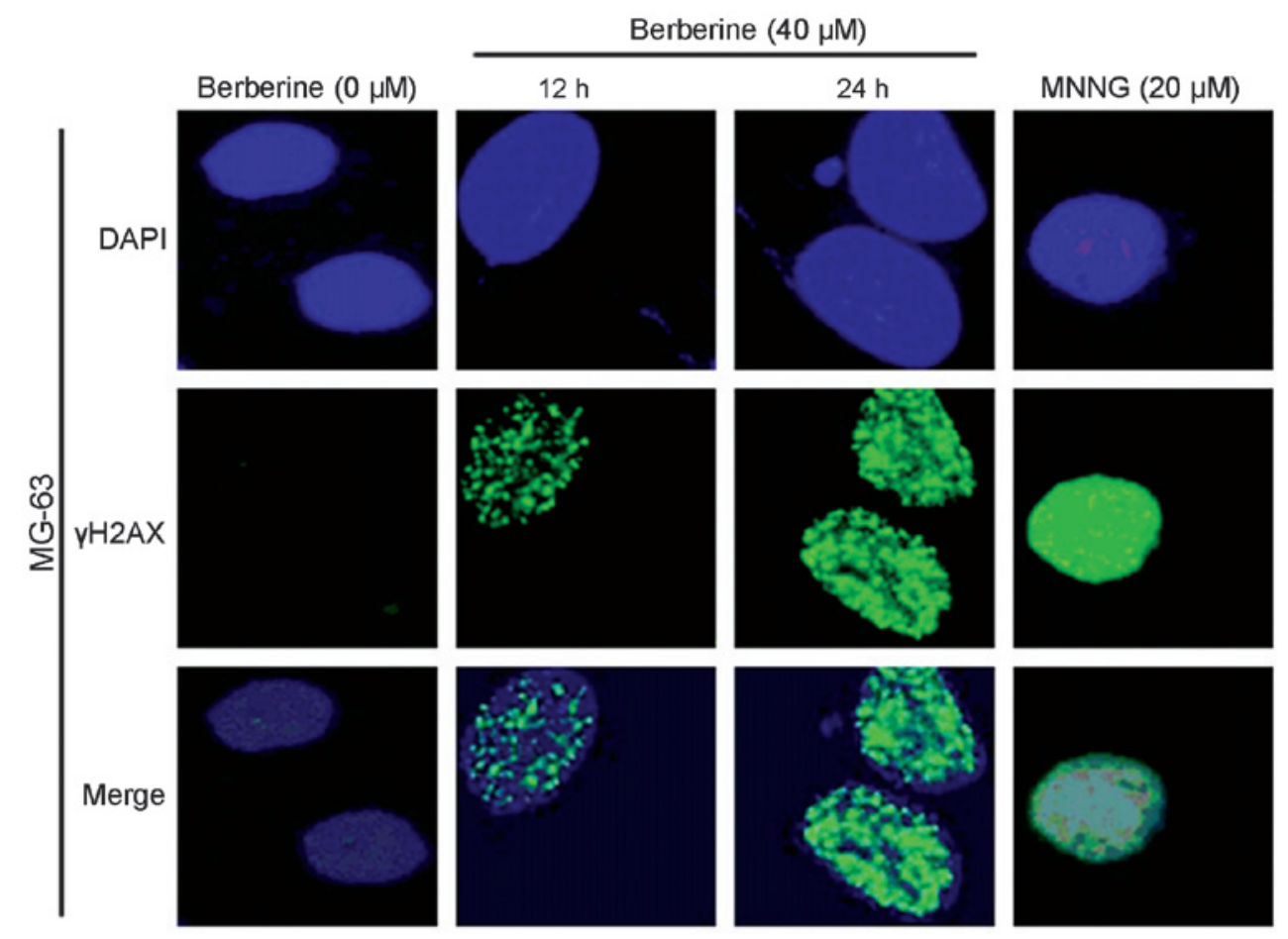

Figure 4. DNA double-strand breaks as illustrated by $\gamma \mathrm{H} 2 \mathrm{AX}$ foci formation in MG-63 cells. Anti- $\gamma \mathrm{H} 2 \mathrm{AX}$ monoclonal antibody was used to detect DNA damage foci immunofluorescence and DAPI was used to stain nuclei (magnification, x400). DAPI, 4',6-diamidino-2-phenylindole; MNNG, methylnitronitrosoguanidine.

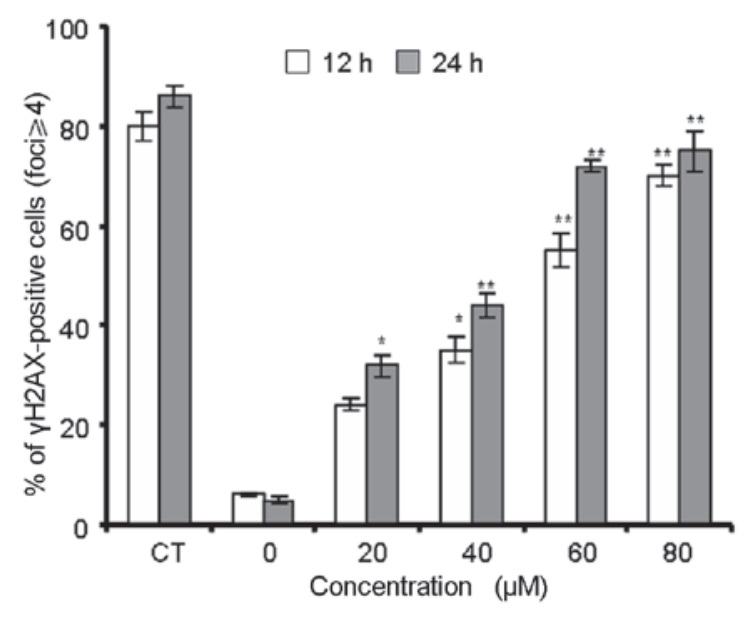

Figure 5. Percentage of $\gamma \mathrm{H} 2 \mathrm{AX}$-positive MG-63 cells treated with $20 \mathrm{mM}$ methylnitronitrosoguanidine (CT) and $0,20,40,60$ or $80 \mathrm{mM}$ berberine for 12 and $24 \mathrm{~h}$. Data are presented as the mean \pm standard error of the mean of three independent experiments. ${ }^{*} \mathrm{P}<0.05$ and ${ }^{* *} \mathrm{P}<0.01$ compared with control

was demonstrated to induce apoptosis and DNA damage of MG-63 cells in a dose- and time-dependent manner. Therefore, berberine acts as a potent genotoxin by inducing marked accumulation of DNA double-strand breaks. The results indicated that treatment with berberine triggered a cascade that includes DNA damage (Fig. 4).

Berberine induced double-strand DNA damage and apoptosis in Ehrlich ascites carcinoma cells (20). Treatment with berberine in vivo resulted in additive cytotoxicity and indicated that berberine has potent antitumor activity against human and rat malignant brain tumors (22). A study involving Saccharomyces cerevisiae demonstrated that berberine exhibited no cytotoxic, mutagenic or recombinogenic activity in non-dividing cells. However, it had significant cytotoxic and cytostatic effects on dividing cells (23). Notably, berberine is more toxic to yeast mutants that are deficient in $\operatorname{rad} 52-1$, suggesting that homologous recombination repair is required for the repair of berberine-induced DNA damage. These results suggest that berberine possesses recombinogenic activity. By contrast, coralyne, a close derivative of berberine, has not been revealed to have detectable mutagenic activity, when analyzed using the Ames test (24). Further studies are required to evaluate the mutagenic activities of berberine.

Berberine has been widely prescribed for the treatment of bacterial diarrhea and has potential applications in several other diseases, including cancer. The findings of the present study demonstrated that berberine causes DNA damage in cultured cells, which raises concerns for its safety in clinical use. However, the present study did not determine whether the induction of apoptosis is directly associated with the genotoxicity of berberine. The mechanisms underlying the genotoxicity of berberine require further investigation to clearly demonstrate that berberine causes genotoxocity and apoptosis. Furthermore, more studies are required to understand the biological consequences of DNA damage on exposure to berberine in vivo. Considering the widespread clinical use of berberine, thorough evaluation of its genotoxocity in vivo is warranted.

\section{References}

1. Mirabello L, Troisi RJ and Savage SA: Osteosarcoma incidence and survival rates from 1973 to 2004: data from the Surveillance, Epidemiology, and End Results Program. Cancer 115: 1531-1543, 2009. 
2. Craig WJ: Health-promoting properties of common herbs. The Am J Clin Nutr 70: 491S-499S, 1999.

3. Sun Y, Xun K, Wang Y and Chen X: A systematic review of the anticancer properties of berberine, a natural product from Chinese herbs. Anticancer Drugs 20: 757-769, 2009.

4. Liu Z, Liu Q, Xu B, et al: Berberine induces p53-dependent cell cycle arrest and apoptosis of human osteosarcoma cells by inflicting DNA damage. Mutat Res 662: 75-83, 2009.

5. Mantena SK, Sharma SD and Katiyar SK: Berberine inhibits growth, induces G1 arrest and apoptosis in human epidermoid carcinoma A431 cells by regulating Cdki-Cdk-cyclin cascade, disruption of mitochondrial membrane potential and cleavage of caspase 3 and PARP. Carcinogenesis 27: 2018-2027, 2006.

6. Katiyar SK, Meeran SM, Katiyar N and Akhtar S: p53 Cooperates berberine-induced growth inhibition and apoptosis of non-smal cell human lung cancer cells in vitro and tumor xenograft growth in vivo. Mol Carcinog 48: 24-37, 2009.

7. Letasiová S, Jantová S, Cipák L and Múcková M: Berberine-antiproliferative activity in vitro and induction of apoptosis/necrosis of the U937 and B16 cells. Cancer Lett 239: 254-262, 2006

8. Meeran S, Katiyar S and Katiyar S: Berberine-induced apoptosis in human prostate cancer cells is initiated by reactive oxygen species generation. Toxicol Appl Pharmacol 229: 33-43, 2008.

9. Hwang JM, Kuo HC, Tseng TH, Liu JY and Chu CY: Berberine induces apoptosis through a mitochondria/caspases pathway in human hepatoma cells. Arch Toxicol 80: 62-73, 2006.

10. Anis KV, Rajeshkumar NV and Kuttan R: Inhibition of chemical carcinogenesis by berberine in rats and mice. J Pharm Pharmacol 53: 763-768, 2001.

11. Nishino H, Kitagawa K, Fujiki $\mathrm{H}$ and Iwashima A: Berberine sulfate inhibits tumor-promoting activity of teleocidin in two-stage carcinogenesis on mouse skin. Oncology 43: 131-134, 1986.

12. Peng PL, Hsieh YS, Wang CJ, Hsu JL and Chou FP: Inhibitory effect of berberine on the invasion of human lung cancer cells via decreased productions of urokinase-plasminogen activator and matrix metalloproteinase-2. Toxicol Appl Pharmacol 214: 8-15, 2006.

13. Kim S, Choi JH, Kim JB, et al: Berberine suppresses TNF-alpha-induced MMP-9 and cell invasion through inhibition of AP-1 activity in MDA-MB-231 human breast cancer cells. Molecules 13: 2975-2985, 2008.
14. Parry MC, Bhabra G, Sood A, et al: Thresholds for indirect DNA damage across cellular barriers for orthopaedic biomaterials. Biomaterials 31: 4477-4483, 2010.

15. Sokolov MV, Smilenov LB, Hall EJ, Panyutin IG, Bonner WM and Sedelnikova OA: Ionizing radiation induces DNA double-strand breaks in bystander primary human fibroblasts. Oncogene 24: 7257-7265, 2005.

16. Liu J, Yang F, Zhang Y and Li J: Studies on the cell-immunosuppressive mechanism of Oridonin from Isodon serra. Int Immunopharmacol 7: 945-954, 2007.

17. Zhao YY, Shen X, Chao X, et al: Ergosta-4,6,8(14), 22-tetraen-3-one induces G2/M cell cycle arrest and apoptosis in human hepatocellular carcinoma HepG2 cells. Biochim Biophys Acta 1810: 384-390, 2011.

18. Guanggang X, Diqiu L, Jianzhong Y, et al: Carbamate insecticide methomyl confers cytotoxicity through DNA damage induction. Food Chem Toxicol 53: 352-358, 2013.

19. Scott EN, Gescher AJ, Steward WP and Brown K: Development of dietary phytochemical chemopreventive agents: biomarkers and choice of dose for early clinical trials. Cancer Prev Res (Phila) 2: 525-530, 2009.

20. Letasiová S, Jantová S, Miko M, Ovádeková R and Horváthová M: Effect of berberine on proliferation, biosynthesis of macromolecules, cell cycle and induction of intercalation with DNA, dsDNA damage and apoptosis in Ehrlich ascites carcinoma cells. J Pharm Pharmacol 58: 263-270, 2006

21. Patil JB, Kim J and Jayaprakasha GK: Berberine induces apoptosis in breast cancer cells (MCF-7) through mitochondria-dependent pathway. Eur J Pharmacol 645: 70-78, 2010.

22. Zhang RX, Dougherty DV and Rosenblum ML: Laboratory studies of berberine used alone and in combination with 1,3-bis(2-chloroethyl)-1-nitrosourea to treat malignant brain tumors. Chin Med J (Engl) 103: 658-665, 1990.

23. Pasqual MS, LauerCP, Moyna P and Henriques JA: Genotoxicity of the isoquinoline alkaloid berberine in prokaryotic and eukaryotic organisms. Mutat Res 286: 243-252, 1993.

24. Cheng CC, Engle RR, Hodgson JR, et al: Absence of mutagenicity of coralyne and related antileukemic agents: structural comparison with the potent carcinogen 7,12-dimethylbenz[a] anthracene. J Pharm Sci 66: 1781-1783, 1977. 